\title{
Argirose ocular e do sistema lacrimal excretor: relato de caso
}

\author{
Eye's and excretory lacrimal apparatus' argyrosis: case report
}

\author{
Abelardo Couto Jr. ${ }^{1}$ \\ Sandra Molles ${ }^{2}$ \\ RicardoSimionato ${ }^{3}$ \\ Daniel Kamlot ${ }^{4}$
}

\begin{tabular}{|l|}
\hline RESUMO \\
\hline No período de março a novembro de 2001, foi diagnosticado um caso de \\
argirose ocular baseando-se na história clínica, no exame biomicroscópico \\
e histopatologia das estruturas oculares. No exame biomicoscópio, \\
observou-se depósitos de pigmentos pardos no estroma corneano e \\
conjuntiva. Na biópsia da conjuntiva, cristalino, canalículo lacrimal \\
superior e saco lacrimal foram encontrados depósitos de prata.
\end{tabular}

Descritores: Argiria; Conjuntiva; Córnea; Oftalmoptias; Aparelho lacrimal; Dacriocistorinostomia; Dacriocistite; Prata; Humano; Feminino; Relatos de casos

\section{INTRODUÇÃ̃O}

A descoloração ocular causada por absorção local ou sistêmica de prata é conhecida como argirose ocular. A argirose caracteriza-se por depósitos de sais de prata nos tecidos cutâneos, descolorando-os ${ }^{(1)}$. Sua aparência histopatológica é bem descrita na conjuntiva e raras no saco lacrimal ${ }^{(2)}$.

É comum após uso crônico de drogas que contenham prata ${ }^{(3-6)}$.

A exposição prolongada à prata produz depósitos em forma de faixa na membrana de Descemet, formando grânulos cinza-azulados, mas não são patognomônicos.

A quantidade de prata na conjuntiva tem relação com o tempo de exposição aos colírios $^{(7)}$. Os depósitos conjuntivais e corneanos são mais intensos na porção inferior e infero-nasal, onde o colírio permanece por mais tempo. No cristalino pode ocorrer uma coloração dourada ou acastanhada na porção subcapsular anterior ${ }^{(1,4)}$. $\mathrm{Na}$ argirose sistêmica, a prata pode depositar-se na membrana de Bruch, dando um aspecto negro à coróide ${ }^{(2)}$.

Alguns autores relataram um caso de argirose na conjuntiva, mais marcante no fórnice inferior e no saco lacrimal. Durante a dacriocistorrinostomia (DCR), encontraram um saco lacrimal de coloração negra e com sinais de processo inflamatório. As culturas foram negativas. No estudo microscópico, encontraram pequenos grânulos castanhos, uniformemente espalhados em pequenos grupos ou em forma de uma banda depositada ao longo das fibras elásticas da submucosa e da membrana basal da mucosa. Estes também foram encontrados na porção basal do epitélio mucoso ${ }^{(8)}$.

Outros autores documentaram prata depositada no saco lacrimal sem comprometer a conjuntiva, após a utilização prolongada de vitelinato de prata. A paciente apresentava dacriocistite crônica. Na microscopia, encontraram grânulos castanho-escuros na submucosa, mas não encontraram no epitélio. Células semelhantes a macrófagos, contendo prata, também foram vistas $^{(3)}$. 


\section{RELATO DE CASO}

R.G.A., 77 anos, branca, feminina, aposentada, natural e procedente do Rio de Janeiro, RJ.

Foi encaminhada, em março de 2001, ao Departamento de Oculoplástica do Instituto Benjamin Constant - RJ.

Relatava epífora desde os seis anos de idade, havia realizado sondagem das vias lacrimais em ambos os olhos (AO). Relatava uso crônico de colírio dos 5 aos 16 anos. Aos 17 anos trocou de oftalmologista, pois o lacrimejamento persistia e seus olhos escureceram. Utilizou colírio de sulfato de zinco por 4 anos para clarear os olhos. Aos 77 anos, a paciente permanecia com epífora, além de baixa visual em AO.

A acuidade visual sem correção no olho direito (OD) de vultos e no olho esquerdo (OE) de 20/80 com trocas.

À biomicroscopia observou-se conjuntiva de coloração amarronzada e depósitos puntiformes no estroma corneano em AO. O OD apresentava catarata cortico-nuclear 4+/4+ e o OE catarata cortico-nuclear e subcapsular posterior de $3+/ 4+$.

$\mathrm{Na}$ tonometria encontrou-se pressão de $11 / 11 \mathrm{mmHg}$ às $14 \mathrm{~h}$.

A fundoscopia revelou-se impossível em AO.

A ultrassonografia ocular revelou retinas aplicadas em AO.

Teste de Zappia Milder: 2+/4+ em AO.

Sondagem diagnóstica: "hard stop" em AO.

Expressão do saco lacrimal: saída de secreção mucopurulenta e sanguinolenta em AO.

Irrigação da via lacrimal sob pressão: não pérvia em AO.

Foi solicitado o exame de dacriocistografia, que revelou obstrução bilateral completa das vias lacrimais ao nível da válvula de Krause e saco lacrimal do tipo II, bilateralmente. Após isso, foi realizada DCR, com biópsia intraoperatória do saco lacrimal do OD.

Após dois meses foi realizada facectomia do OD e coletado material corneano, conjuntival e do cristalino para estudo histopatológico. Quatro meses após a facectomia do OD foi realizada a DCR do OE e coletado material para estudo histopatológico do saco lacrimal, canalículo lacrimal superior esquerdo e conjuntiva bulbar inferior de AO.

Durante a DCR do OD, observou-se um saco lacrimal de coloração negra (Figura 1). E realizou-se a biópsia do saco lacrimal (Figura 2).

\section{Descrição macroscópica}

No saco lacrimal foram encontrados quatro fragmentos enegrecidos e nas outras regiões biopsiadas, um diminuto fragmento de tecido pardo-escuro e elástico.

\section{Conclusão microscópica consolidada}

Processo inflamatório crônico com intenso infiltrado de células linfóides típicas e depósitos de material castanho-escuro ou negro compatível com argirose. Ausência de malignidade.

Tais achados foram observados nas amostras do saco lacrimal e conjuntiva bulbar inferior de AO, córnea - porção periférica superior, conjuntiva perilimbar superior e cristalino do OD, e no canalículo lacrimal superior do OE.

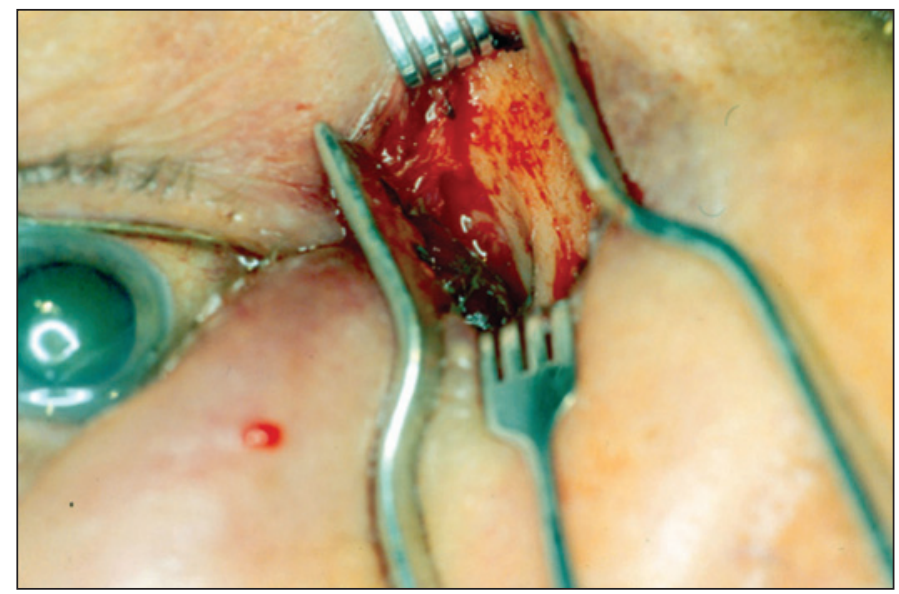

Figura 1 - Dacriocistorrinostomia do OD. Saco lacrimal de coloração negra.

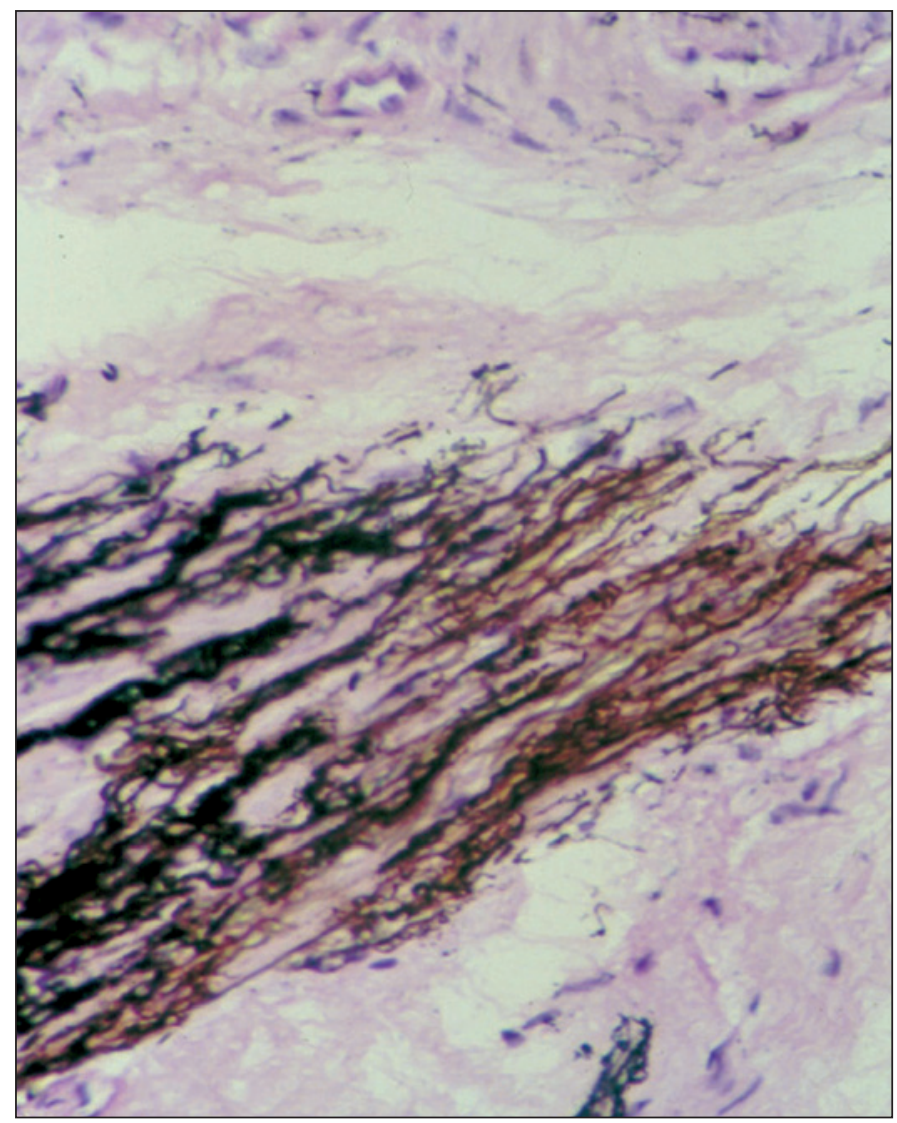

Figura 2 - Saco lacrimal direito. Coloração pela HE. Aumento: Objetiva de 24x. Depósito de material castanho-escuro sob forma de grumos ou com aspecto fibrilar (depósitos de prata).

\section{DISCUSSÃO}

A argirose ocular é bem documentada pelo uso prolongado de colírios que contenham prata. A prata já foi usada cosmeticamente e na prevenção da oftalmia neonatal ${ }^{(3)}$. O vitelinato de prata $\left(\right.$ Argirol $\left.^{\circledR}\right)$ foi originalmente criado para uma ação antibacteriana. 
No caso relatado, a paciente fez uso de vitelinato de prata de forma contínua por mais de dez anos, e apresentava obstrução das vias lacrimais, semelhante aos estudos de alguns autores. Estes dados associados aos achados clínicos nos levaram à hipótese diagnóstica de argirose ocular ${ }^{(3,8)}$.

No intraoperatório foi observado um processo inflamatório no saco lacrimal, e posteriormente confirmado no histopatológico. Também relatado nesses estudos. O saco lacrimal apresentava uma coloração negra, descrita por autores como sendo pintada com tinta da Índia. Foi afastada a hipótese de malignidade que indicaria uma dacriocistectomia e não uma DCR com biópsia ${ }^{(3,8)}$.

Na biomicroscopia, observou-se a coloração acinzentada da conjuntiva, mais intensa no fórnice inferior, descrita por vários autores. Neste caso o fator obstrutivo permitia um maior tempo de contato da droga no fórnice inferior e no saco lacrimal, aumentando assim a absorção e impregnação da prata nos tecidos ${ }^{(6,8)}$.

A comprovação da argirose foi feita pela biópsia realizada na conjuntiva bulbar inferior de $\mathrm{AO}$, nos sacos lacrimais de $\mathrm{AO}$ e canalículo lacrimal superior do OE. Todos mostraram aspecto histológico semelhante com impregnação sob forma de grumos ou aspecto fibrilar por material de coloração castanho-escura, relatado em estudos sobre o saco lacrimal. Os dois estudos afirmam que o depósito ocorre principalmente no tecido fibroelástico ${ }^{(3,8)}$.

No cristalino do OD, observou-se, em uma das superfícies da lente, depósito de coloração parda. Segundo estudos, a porção subcapsular anterior do cristalino pode apresentar uma coloração dourada ou acastanhada ${ }^{(1)}$.

A negatividade das biópsias realizadas na conjuntiva e córnea perilimbar superior é explicada devido aos locais biopsiados serem as áreas menos expostas à droga, como relatado por autores. Relatam também, que a maior ocorrência de impregnação é no fórnice inferior e na córnea inferior, expostos por um período maior. Outros autores relatam a importância do diagnóstico diferencial da argirose conjuntival com lesões melanocíticas conjuntivais benignas e malignas, incluindo o melanoma $^{(7,9)}$.

Provavelmente a impregnação pela prata deve ocorrer em mais estruturas, conjuntiva, córnea, cristalino, mas o saco lacrimal obstruído permanece em contato por mais tempo com a droga.
É importante salientar que na literatura pesquisada, até o momento, não há relato de impregnação de prata nos canalículos lacrimais. Talvez, este fato pode ter ocorrido por eles não terem sido biopsiados. Breve descrição de argirose conjuntival foi relatada em anais de Congresso Oftalmológico ${ }^{(10)}$.

\section{ABSTRACT}

From March to November 2001, a case of eye's argyrosis was diagnosed based on clinical history, eye's biomicroscopy and histopathology. In the biomicroscopy exam, there were gray deposits of pigments in corneal stroma and conjunctiva. In the incisional biopsy of conjuctiva, lens, upper lacrimal canaliculi and lacrimal sac deposits of silver were found.

Keywords: Argyria; Conjunctiva; Cornea; Eye diseases; Lacrimal apparatus; Dacryocystorhinostomy; Dacryocystitis; Silver; Human; Female; Case reports

\section{REFERÊNCIAS}

1. Moss AP, Sugar A, Hargett NA, Atkin A, Wolkstein M, Rosenman KD. The ocular manifestations and functional effects of occupational argyrosis. Arch Ophthalmol. 1979;97(5):906-8.

2. Cohen SY, Quentel G, Egasse D, Cadot M, Ingester-Moati I, Coscas GJ. The dark choroid in systemic argyrosis. Retina. 1993;13(4):312-6.

3. Loeffler KU, Lee WR. Argyrosis of the lacrimal sac. Graefes Arch Clin Exp Ophthalmol. 1987;225(2):146-50.

4. Grayson M. Enfermidades de la córnea. $2^{\underline{a}}$ ed. Buenos Aires: Medica Panamericana; 1985. Cap.24 - Drogas, metales y pigmentacione.

5. Gutman MD, Crosswell HH Jr. Argyrosis of the cornea without clinical conjunctival involvement. Am J Ophthalmol. 1996;65(2):183-7.

6. Hodson TJ, Gillies WE. Argyrol, argyrosis and the acquisition of art. Aust N Z J Ophthalmol. 1985;13(4):391-4.

7. Hanna C, Fraunfelder FT, Sanchez J. Ultrastructural study of argyrosis of the cornea and conjunctiva. Arch Ophthalmol. 1974;92(1):18-22.

8. Yanoff M, Scheie HG. Argyrosis of the conjunctiva and lacrimal sac. Arch Ophthalmol. 1964;72:57-8.

9. Gallardo MJ, Randleman JB, Price KM, Johnson DA, Acosta S, Grossniklaus $\mathrm{HE}$, et al. Ocular argyrosis after long-term self-application of eyelash tint. Am J Ophthalmol. 2006;141(1):198-200.

10. Silva JC, Lima JA, Neto PS. Argirose conjuntiva. Arq Bras Oftamol. (Supl 4): 87. [Apresentado no $16^{\circ}$ Congresso Brasileiro de Prevenção da Cegueira e Reabilitação Visual; 2004 Set 4-7, Rio de Janeiro, 4-7 set. Anais. 